\title{
Investigating the Efficiency of Vitamin D Administration with Buccal Spray in the Treatment of Vitamin D Deficiency in Children and Adolescents
}

\author{
(D) Özlem Nalbantoğlu, (D) Sezer Acar, (D) Gülçin Arslan, (D) Özge Köprülü, (D) Behzat Özkan \\ University of Health Sciences Turkey, Dr. Behçet Uz Child Diseases and Pediatric Surgery Training and Research Hospital, Clinic of Pediatric \\ Endocrinology, izmir, Turkey
}

\begin{abstract}
What is already known on this topic?
The main purpose of vitamin D therapy is to optimize serum 25-hydroxyvitamin D [25(OH)D] concentrations to improve bone homeostasis and decrease the risk of osteopenia and osteoporosis. Daily or weekly oral drops or a single large dose, either orally or through injection are used more frequently in the treatment of vitamin D deficiency. There are limited numbers of studies that have evaluated the effectiveness of buccal spray against other modes of vitamin D delivery in the treatment of vitamin D deficiency in children and the results of these studies are conflicting.
\end{abstract}

\section{What this study adds?}

Vitamin D3 supplementation with buccal spray and oral drops is equally effective in terms of raising serum $25(\mathrm{OH}) \mathrm{D}$ concentrations in short-term treatment of vitamin D deficiency.

\begin{abstract}
Objective: The aim of this study was to evaluate the efficiency of a buccal spray form of vitamin D compared to single oral dose (stoss therapy) and oral drops therapy in the treatment of vitamin D deficiency.

Methods: Ninety healthy children and adolescents (3-18 years) with vitamin D deficiency [serum level of 25-hydroxyvitamin D (25(OH) D) $<12 \mathrm{ng} / \mathrm{mL}$ ] were randomized to receive vitamin D3 buccal spray (2000 $\mathrm{U}, \mathrm{n}=30$, group 1) for six weeks, oral drops (2000 U, $\mathrm{n}=30$, group 2) for six weeks and a single oral dose (300 $000 \mathrm{U}$ ) vitamin D3 ( $\mathrm{n}=30$, group 3). Serum calcium, phosphorus, alkaline phosphatase, parathyroid hormone and $25(\mathrm{OH}) \mathrm{D}$ levels of the patients were measured at baseline and after the treatment on the $42^{\text {nd }}$ day.

Results: All three groups had a significant increase in serum 25(OH)D concentrations $(\mathrm{p}<0.001)$. In group 1 , baseline mean 25(OH)D was $8.0 \pm 0.41 \mathrm{ng} / \mathrm{mL}$, which rose to $22.1(17.8-28.2) \mathrm{ng} / \mathrm{mL}$ after treatment with a mean increase of $15.6 \pm 1.3 \mathrm{ng} / \mathrm{mL}$. Similarly in group 2 , baseline, post-treatment and mean increase in $25(\mathrm{OH}) \mathrm{D}$ concentrations were $7.9 \pm 0.45 \mathrm{ng} / \mathrm{mL}, 24.4(20.6-29.6) \mathrm{ng} / \mathrm{mL}$ and $17.3 \pm 1.1$ $\mathrm{ng} / \mathrm{mL}$ while for group 3 these values were $7.6 \pm 0.47 \mathrm{ng} / \mathrm{mL}, 40.3(29.4-58.4) \mathrm{ng} / \mathrm{mL}$ and $34.3 \pm 3.2 \mathrm{ng} / \mathrm{mL}$, respectively.

Conclusion: We conclude that vitamin D3 supplementation with buccal spray and oral drops is equally effective in terms of raising vitamin D concentrations in short-term treatment of vitamin D deficiency.
\end{abstract}

Keywords: Vitamin D, buccal spray, 25-hydroxyvitamin D, oral drops

\section{Introduction}

Vitamin D is a pro-hormone for active intestinal calcium (Ca) absorption, and it plays a major role in maintaining $\mathrm{Ca}$ and phosphorous homeostasis and skeletal integrity (1). Deficiency of vitamin D leads to rickets, the failure of mineralization of growing bone in children and osteomalacia in adults (1). Meanwhile, it has been reported that vitamin D deficiency may be associated with chronic diseases such as cardiovascular diseases, diabetes, hypertension and autoimmune diseases, among others $(2,3,4,5,6,7,8,9,10)$. So, treatment of vitamin D deficiency and thus, maintenance
Address for Correspondence: Özlem Nalbantoğlu MD, University of Health Sciences Turkey, Dr. Behçet Uz Child Disease and Pediatric Surgery Training and Research Hospital, Clinic of Pediatric Endocrinology, İzmir, Turkey Phone: +90506 5944040 E-mail: ozlemnalbantmd@yahoo.com ORCID: orcid.org/0000-0002-0410-5761
Conflict of interest: None declared Received: 25.02 .2021 Accepted: 19.05 .2021

${ }^{\circ}$ Copyright 2021 by Turkish Pediatric Endocrinology and Diabetes Society

The Journal of Clinical Research in Pediatric Endocrinology published by Galenos Publishing House. 
of 25-hydroxyvitamin $\mathrm{D}[25(\mathrm{OH}) \mathrm{D}]$ concentrations in the normal range, as advised by several expert committees to provide optimal tissue health, is very important.

Numerous reported consensus reports on vitamin D therapy have been published by many organizations around the world $(11,12,13,14,15)$. In these consensus reports, different treatment algorithms are recommended for vitamin D deficiency in healthy children with or in those with chronic diseases, such as celiac disease, inflammatory bowel diseases, and cystic fibrosis. For healthy children, different treatment regimens, such as daily, weekly or a single dose (stoss) with cumulative vitamin $\mathrm{D}$ dose ranging from 84,000 to 600,000 IU are recommended $(11,12,13,14,15)$. The recommended treatment duration of daily or weekly treatment regimens can range from 6 to 12 weeks. In these treatment protocols, vitamin D is usually given as cholecalciferol (vitamin D3) rather than ergocalciferol (vitamin D2), and as oral low-dose long-term therapy or oral/ intramuscular high-dose injection (stoss therapy). However, both treatment protocols have their own disadvantages. Although low-dose long-term therapy varies, depending on the dose, the treatment duration can be up to three months. This situation often causes problems in compliance with treatment. In addition, in cases of malabsorption, such as in patients with celiac disease, a problem occurs in the dose adjustment required for the desired serum level. Recently, novel treatment modalities have been developed for the treatment of vitamin D deficiency, including an oral spray, soft capsule, gels, and gums (16). Most of the studies comparing different vitamin D treatment modalities were conducted with adults $(1,17,18)$, and there are limited studies conducted in children $(19,20)$. In most of these studies, in which capsule, drop and spray forms of vitamin D were compared, it was shown that different treatment modes did not have superiority to each other $(16,17,18)$, but in one study the oral spray form was reported to be more effective (1). These studies are heterogeneous in terms of treatment dose and duration, population age, study design and health status, which make it difficult to draw assumptions from the results. Therefore, in this study, we aimed to evaluate the efficiency of the buccal spray form of vitamin D compared to single oral dose (stoss therapy) and oral drops therapy in the treatment of vitamin D deficiency.

\section{Methods}

\section{Study Population}

This study was conducted in children diagnosed with vitamin D deficiency aged between 3-18 years old who were treated in University of Health Sciences Turkey, Dr. Behçet
Uz Children's Hospital between January-March 2020. The exclusion criteria were: hepatic or renal failure; uncontrolled hypothyroidism or hyperthyroidism; systemic inflammatory or malignant disease; vegan diet; or had a confirmed diagnosis of a malabsorptive condition including ulcerative colitis, Crohn's disease or steatorrhea. In addition, patients using medication known to influence vitamin D metabolism (bisphosphonates, glucocorticoids and anticonvulsants) and those who had been on a sun holiday in the 30 days prior to baseline measurements or those planning a sun holiday during the time of the study, or using medication known to affect bone metabolism were also excluded. Women who were pregnant or attempting to become pregnant during the study period were also excluded. The Local Ethics Committee approved the study (University of Health Sciences Turkey, Dr. Behçet Uz Children's Hospital, Clinical Research Ethics Committee, İzmir; approval number: 2018/17-12), and written informed consent was obtained from all individuals involved.

\section{Baseline Data Collection}

Age, sex, height and weight of all cases were evaluated. A Harpenden stadiometer with sensitivity of $0.1 \mathrm{~cm}$ was used for measurement of height. Body weight measurement was performed using a scale with sensitivity of $0.1 \mathrm{~kg}$ (SECA, Hamburg, Germany). All measurements made by the same person. The patients took off their shoes and wore light clothes before the measurement. Body mass index (BMI) was calculated by dividing the weight in kilograms by the square of the height in meters $\left(\mathrm{m}^{2}\right)$. BMI percentiles and Z-scores were determined by using reference data for Turkish children, according to age and sex $(21,22)$. Children with a BMI equal to or greater than the $95^{\text {th }}$ percentile were considered obese.

Baseline fasting blood samples including serum $\mathrm{Ca}$, phosphorus (P), alkaline phosphatase (ALP), 25(OH)D, albumin, blood urea nitrogen (BUN), serum creatinine, alanine aminotransferase (ALT), and aspartate aminotransferase (AST) were collected. Serum 25(OH)D levels and parathyroid hormone (PTH) were measured by the electrochemiluminescence method. This assay was carried out through quantitative determinations of total 25(OH)D in serum samples using a standard kit available for the Abbott Architect system, (Abbott Laboratories, IL, USA). Serum Ca, P, ALP, albumin, BUN, serum creatinine, ALT, and AST were also measured in duplicate and assessed using an Architect C system biochemistry analyzer (Abbott Laboratories, IL, USA).

In this study, the following classifications were used: Serum vitamin D level $>20 \mathrm{ng} / \mathrm{mL}$ is regarded as "sufficient", $<12$ 
$\mathrm{ng} / \mathrm{mL}$ is regarded as deficient, and $12-20 \mathrm{ng} / \mathrm{mL}$ is regarded as "insufficiency" $(11,23)$. Written and signed consent was obtained from the parents of the participants $<12$ years old who met the criteria and agreed to participate in the study, and from both parents and children in those older than 12 years.

Patients with vitamin D deficiency who met the inclusion criteria were included in each group sequentially. A total of 90 patients (30 patients in each group) were included in the study between January 2020 and March 2020. The first group (group I) was treated with buccal spray (Wellcare vitamin D3, 1 puff equals $1000 \mathrm{U}$ ), the second group (group 2) was treated with vitamin D-containing drops (Devit3 oral drop, 1 drop is approximately133 U) and the third group (group 3) was treated with a single oral dose of vitamin D from an ampoule (Devit3 ampoule). In group 1, patients received 2000 IU/day (two puffs) for six weeks; while in group 2 patients received 2000 IU/day (15 drops) for six weeks. The patients in group 3 were treated with a single dose of vitamin D (300,000 IU single oral dose). All participants kept a record of the intake time and the amount of the medication they used. They were told that if they forgot to take the drops or spray, they would take the missing dose when they remembered. Blood samples of all three groups were obtained and analysed at the end of the treatment period of six weeks ( $42^{\text {nd }}$ day).

\section{Statistical Analysis}

Statistical analyses of the data were performed using Statistical Package for the Social Sciences, version 20.0 (IBM Corp., Armonk, NY, USA). Distribution of data was evaluated using the Kolmogorov-Smirnov test. For comparison of more than two groups, one-way ANOVA or KruskalWallis test were used as appropriate for the distribution of the data. If a significant difference was found in the comparison of more than two groups, Mann-Whitney U test with Bonferroni correction or Tukey test were performed as a post-hoc test to determine where the differences truly originated. In the comparison of two dependent groups (for pre- and post-treatment measurements), paired t-test or Wilcoxon test were performed according to distribution of the parameters. The chi-square test was used to compare categorical variables. Spearman's rho correlation was used to identify the associations between BMI standard deviation score (SDS), post-treatment serum 25(OH)D levels and the amount of increase in $25(\mathrm{OH}) \mathrm{D}$ levels. Categorical data were expressed as frequency (\%), while numerical data were expressed as median (25-75 $5^{\text {th }}$ percentile) or mean \pm standard deviation. A value of $p<0.05$ was considered significant.

\section{Results}

The mean ages were $12.1 \pm 4.1,10.8 \pm 3.6,11.9 \pm 3.9$ years in groups 1,2 and 3 , respectively $(p>0.05)$. Of the 90 participants, 29 (32.2\%) were male, and 61 (67.8\%) were female. Sex distribution in each group was as follows: group $111(36.7 \%)$ male and $19(63.3 \%)$ female while in groups 2 and 3 there were $9(30 \%)$ male and 21 (70\%) female participants. The anthropometric and demographic data of participants are shown in Table 1 . There was no difference in sex, age, weight, height, weight SDS, height SDS, or BMI SDS between the three groups $(p>0.05)$.

Baseline and post-treatment Ca, P, ALP, PTH, 25(OH)D values are shown in Table 2. All participants were normo-calcemic, therefore none of them received Ca supplementation. There was no statistically significant difference between the three groups in terms of the baseline or post-treatment Ca, P, ALP, $\mathrm{PTH}$. In contrast, both the post-treatment levels of serum $25(\mathrm{OH}) \mathrm{D}$ and the degree of increase in serum 25(OH)D levels after treatment were significantly higher in group 3 $(p<0.001)$.

When the baseline and post-treatment values of the parameters were compared, while serum 25(OH)D levels increased and PTH levels decreased in all three groups

\begin{tabular}{|c|c|c|c|c|}
\hline Parameters & Group 1 & Group 2 & Group 3 & $\mathrm{p}$ \\
\hline $\begin{array}{l}\text { Sex, n (\%) } \\
\text { Male } \\
\text { Female }\end{array}$ & $\begin{array}{l}30 \\
11(36.7 \%) \\
19(63.3 \%)\end{array}$ & $\begin{array}{l}30 \\
9(30 \%) \\
21(70 \%)\end{array}$ & $\begin{array}{l}30 \\
9(30 \%) \\
21(70 \%)\end{array}$ & $0.816^{\mathrm{a}}$ \\
\hline Age (years) & $12.1 \pm 4.1$ & $10.8 \pm 3.6$ & $11.9 \pm 3.9$ & $0.411^{\mathrm{b}}$ \\
\hline Weight (kg) & $45.2(30.6-56.0)$ & $40.6(29.8-56.6)$ & $47.2(28.2-56.4)$ & $0.823^{c}$ \\
\hline Weight SDS & $-0.05 \pm 0.24$ & $0.02 \pm 0.20$ & $-0.13 \pm 0.17$ & $0.868^{b}$ \\
\hline Height SDS & $-0.40 \pm 0.19$ & $-0.12 \pm 0.18$ & $-0.31 \pm 0.18$ & $0.561^{\mathrm{b}}$ \\
\hline BMI SDS & $0.13 \pm 0.22$ & $0.72 \pm 0.21$ & $-0.50 \pm 0.18$ & $0.815^{\mathrm{a}}$ \\
\hline
\end{tabular}

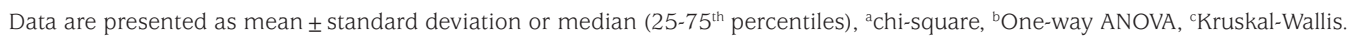

BMI: body mass index, SDS: standard deviation score 
$(p<0.05)$ and serum ALP levels decreased in group 1 only $(p<0.05)$, no statistically significant change in serum $\mathrm{Ca}$ and $P$ levels were found between groups.

At the end of the treatment, $20(66.7 \%)$ patients in group 1, $26(86.7 \%)$ patients in group 2 and $27(90 \%)$ patients in group 3 had normal ( $>20 \mathrm{ng} / \mathrm{mL}$ ) serum 25(OH)D levels $(p=0.044)$. In the remaining patients, serum $25(\mathrm{OH}) \mathrm{D}$ levels were in the insufficient range of 12-20 $\mathrm{ng} / \mathrm{mL}$. Six cases in group 1, and 3 cases in each of group 2 and 3 were obese $(p=0.421)$. Serum $25(\mathrm{OH}) \mathrm{D}$ level at the end of treatment was sufficient in 4 of 6 obese patients in group 1 , in all obese patients in group 2 , and in 2 of 3 obese patients in group 3 ( $p>0.05$ ). There was no correlation between the amount of increase in $25(\mathrm{OH}) \mathrm{D}$ level and BMI SDS in groups 1,2 and 3 ( $p>0.05)$.

\section{Discussion}

In the current study, a single oral dose treatment of 300,000 IU was superior to 2000 IU of oral drop vitamin D3 daily for six-weeks or 2000 IU of buccal spray vitamin D3 daily for six weeks treatments in increasing serum $25(\mathrm{OH}) \mathrm{D}$ levels. Moreover, oral drop and buccal spray treatments were found to be similarly effective in raising serum vitamin $D$ levels. In three groups with similar baseline serum $25(\mathrm{OH})$ $\mathrm{D}$ levels, however, the proportion of patients with normal serum 25(OH)D levels ( $>20 \mathrm{ng} / \mathrm{mL}$ ) at the end of treatment was lower with buccal spray treatment $(66.7 \%)$ compared to oral drops $(86.7 \%)$ or 300000 IU oral single dose $(90 \%)$ treatments. Malabanan et al (24) reported that vitamin D supplementation using 50,000 IU weekly for eight weeks was successful in the treatment of vitamin D deficiency in older children and adolescents. In another study conducted in healthy infants and young children with hypovitaminosis $\mathrm{D}$, patients were divided into three different groups that received either 2,000 IU oral vitamin D2 daily, 50,000 IU vitamin D2 weekly or 2,000 IU vitamin D3 daily, and these three regimens were compared. All three treatment regimens were applied for six weeks and were shown to

Table 2. Baseline and post-treatment laboratory characteristics of patients

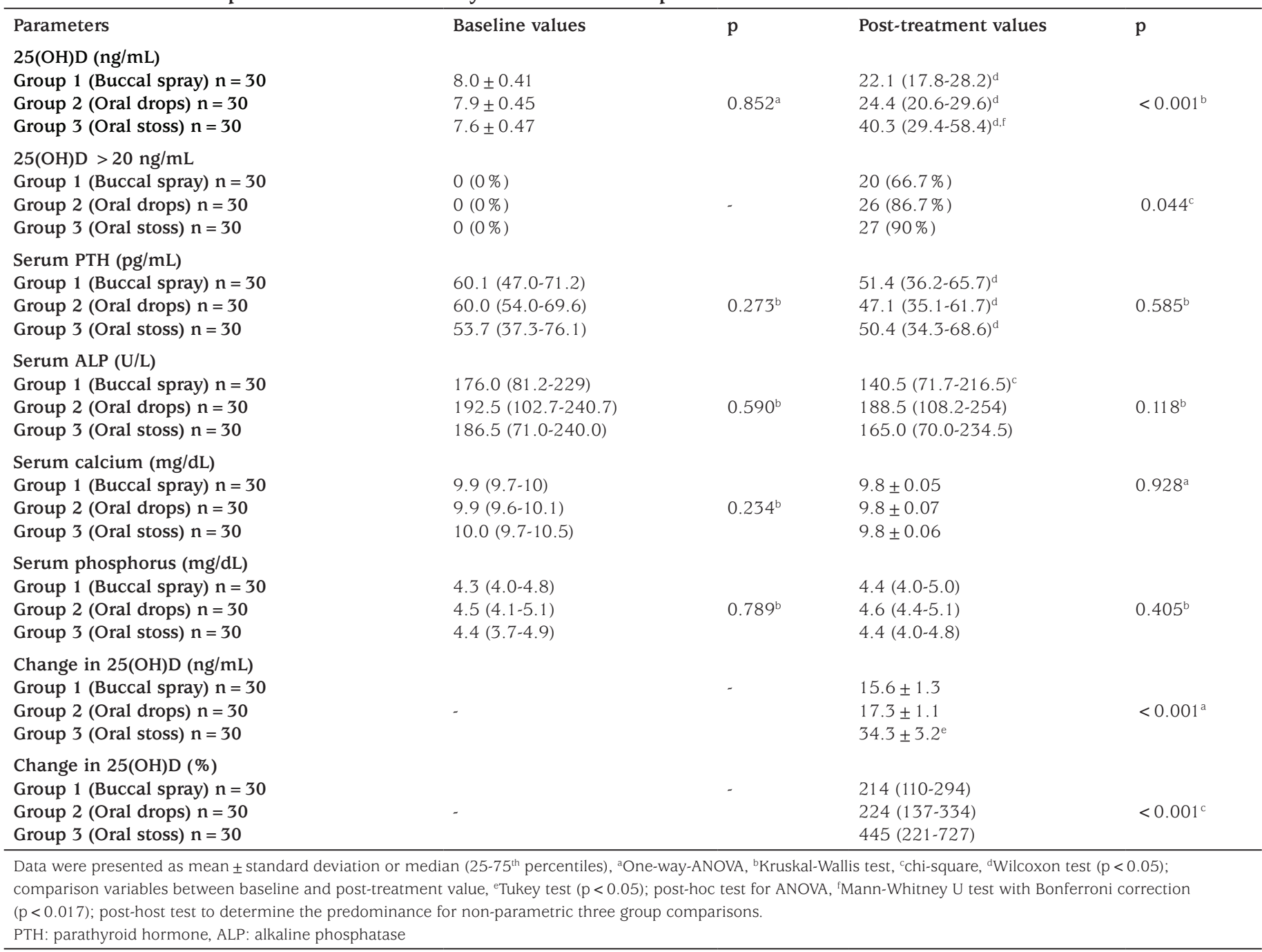


give equivalent results in the short-term treatment of hypovitaminosis $\mathrm{D}$ among healthy infants and young children (25). Pappa et al (26) found that both 2,000 IU of daily vitamin D3 and 50,000 IU of weekly vitamin D2 were superior to 2,000 IU of daily vitamin D2, all taken orally for six weeks, in raising serum $25(\mathrm{OH}) \mathrm{D}$ concentration in young patients with inflammatory bowel disease and vitamin D insufficiency. When all these studies and the current study are evaluated, an inference can be made that 2,000 IU oral vitamin D3 per day, 50,000 IU oral weekly treatment for 6-8 weeks and 300,000 IU oral single dose treatment are effective in the treatment of vitamin D deficiency.

There are studies suggesting that new treatment modalities, such as buccal spray, are as effective as oral drops in this treatment $(1,16,17,18,19)$. Satia et al (1) compared the absorption of vitamin D3 through the oral route by comparing buccal spray and gelatin capsule in healthy adults and patients with malabsorption disease. All participants in groups were randomized to receive either the vitamin D3 buccal spray (2 sprays, each of 500 IU) or soft gelatin capsule containing vitamin D3 (1000 IU) for 30 days. After the completion of the 30-day treatment, all participants were given a 30-day washout. In the second period, crossover was performed so that those participants who had received the buccal spray formulation in period I received the soft gelatin capsule formulation in period 2 and vice versa. In this study, the superiority of vitamin D3 delivery via buccal spray compared to capsules in both healthy subjects as well as in patients with intestinal malabsorption syndrome was reported. On the other hand, the trial had limitations regarding the washout duration. Todd et al (17) compared the efficacy of vitamin D3 liquid capsules and oral spray solution in increasing wintertime total $25(\mathrm{OH}) \mathrm{D}$ concentrations in a randomized, open-label, cross-over trial in healthy adults. Twenty-two healthy adults received 3000 IU $(75 \mu \mathrm{g})$ vitamin D3 daily, for four weeks in either capsule or oral spray form. After 10 days wash-out period, participants received the other treatment for four weeks. They demonstrated that oral spray vitamin D3 was just as effective as capsule supplementation in increasing total serum $25(\mathrm{OH}) \mathrm{D}$ concentrations in the healthy adult population. Penagini et al (19) demonstrated that vitamin D3 supplementation with buccal spray and oral drops was equally effective in the short-term treatment of vitamin D deficiency in a population of children with neurodisabilities. In this study, patients received vitamin D3 buccal spray 800 IU/daily $(n=12)$ and a second group received oral drops 750 IU/daily $(n=12)$ for three months during winter. Williams et al (18) conducted a randomized, placebo-controlled, threearm parallel design study in healthy volunteers to compare the rate of change of vitamin $\mathrm{D}$ status in response to vitamin D3 (3000 IU/day) supplementation in capsule and sublingual spray preparations over a six week period. They suggested that sublingual vitamin D spray was an effective mode of delivery for supplementation in a healthy population and the capsule and spray were equally efficacious. When all these studies are considered, only Satia et al (1) advocated the superiority of buccal spray vitamin $\mathrm{D}$ against the other modes of delivery in increasing serum 25(OH)D concentrations.

Recent systematic reviews demonstrated that the administration of vitamin D3 by buccal spray did not differ from other supplementation methods in increasing serum plasma $25(\mathrm{OH}) \mathrm{D}$ levels $(16,27)$. However, the small number of randomized controlled trials and the high degree of clinical heterogeneity of study populations did not allow for any reliable conclusions to be drawn from the results (16). In the study of Unsur (20), in which evaluated infants received 400 IU/day vitamin D supplementation as oral drops or buccal spray form during the first year of life, it was reported that the serum 25(OH)D levels measured at the age of one year were higher and the frequency of vitamin D deficiency was lower in infants using buccal spray than those using oral drops. In the current study, the group receiving stoss vitamin $D$ had a significantly higher mean increase than both groups receiving buccal spray or oral drops. However, there was no significant difference in terms of increase in 25(OH)D levels between the group receiving buccal spray and oral drops. It was notable that when $25(\mathrm{OH}) \mathrm{D}$ levels of the three groups were evaluated at the end of the treatment, the proportion of patients with normal $25(\mathrm{OH}) \mathrm{D}$ level in the buccal spray group was smaller than in the oral drops group despite the same dose and duration $(66.7 \%$ vs $86.7 \%)$. This suggests that in cases with a 25(OH)D level of $<12 \mathrm{ng} / \mathrm{mL}, 2000 \mathrm{IU} /$ day 6-week spray therapy may be insufficient.

It is well recognized that there are various factors that affect the effectiveness of vitamin D therapy other than the route of administration or dose (14). Dark skinned children, reduced sunlight exposure due to constant use of sunscreens or lifestyle factors, covering clothing for religious or cultural reasons, chronic illness, obesity, malabsorption syndromes, drugs such as anticonvulsants, systemic glucocorticoids, antiretroviral therapy, and systemic antifungals can all affect the success of treatment (14). The Institute of Medicine does not take BMI into account in recommendations for vitamin D treatment, however the Clinical Practice Guidelines by the Endocrine Society recommend obese subjects be given two to three times more vitamin $\mathrm{D}$ to satisfy their body's vitamin D requirement. In a study in adults, it was shown that supplementation efficiency is associated with 
BMI. In participants with normal body weight a greater change in serum 25(OH)D level was observed (28). Ekwaru et al (29) recommended 2- to 3-times higher vitamin D supplementation for obese subjects and 1.5 times higher for overweight subjects relative to normal weight subjects. Although the association between vitamin D deficiency and obesity and obesity-related diseases has been confirmed by numerous studies, the existence of a causal relationship is still unclear. In the current study, no significant relationship between obesity and the success of vitamin D therapy was found, although only 12 of 90 (13.3\%) subjects were obese in our study.

\section{Study Limitations}

Our study has some limitations that should be acknowledged. The first limitation was the small sample size. In defence of this, the current study was conceived as a pilot study to assess the three different modes of vitamin D administration, buccal spray, oral drops and oral stoss vitamin D. The second limitation of our study was that the vitamin D binding protein (VDBP) status was unknown in all patients. Genetic variants not only affect vitamin D metabolism, but also affect the phenotype of the VDBP with different affinities to 25(OH)D and 1,25-(OH)2 D3 (23). Genetic polymorphisms of DBP can also alter the protein concentration in blood (30). Furthermore, assessment of VDBP polymorphisms may be useful to adjust treatment in individuals with an insufficient response to vitamin D supplementation. Genetic factors may be taken into account in the future design of personalized supplementation. Additionally, while all patients were living at the same latitude, the impact of intake of vitamin D containing foods, duration of breastfeeding, clothing, and exposure to sunlight were not considered. Finally, the patients' compliance to treatment (especially those receiving daily oral or buccal vitamin D treatment) was evaluated on the basis of self-reporting and most of the patients were adolescents and it is well-known that low adherence to treatment at this age is very common, which may have skewed the results, especially in groups 1 and 2 .

\section{Conclusion}

The results of this study show that a single dose 300,000 IU vitamin D3 formulation was able to increase mean serum vitamin D3 concentration significantly compared to 2000 IU/day for six weeks given either by buccal spray or oral drops in both healthy children and adolescents. Vitamin D3 supplementation with buccal spray and oral drops was equally effective in terms of raising vitamin $\mathrm{D}$ concentration in the short-term treatment of vitamin $\mathrm{D}$ deficiency. However, in cases with a baseline serum level of $25(\mathrm{OH})$
D $<12 \mathrm{ng} / \mathrm{mL}$, treatment with 2000 IU/day for six weeks given by buccal spray may be insufficient to normalize serum 25(OH)D in a significant proportion of patients.

\section{Ethics}

Ethics Committee Approval: The Local Ethics Committee approved the study (University of Health Sciences Turkey, Dr. Behçet Uz Children's Hospital, Clinical Research Ethics Committee, İzmir; approval number: 2018/17-12).

Informed Consent: Consent form was filled out by all participants.

Peer-review: Externally peer-reviewed.

\section{Authorship Contributions}

Surgical and Medical Practices: Özlem Nalbantoğlu, Sezer Acar, Gülçin Arslan, Özge Köprülü, Behzat Özkan, Concept: Özlem Nalbantoğlu, Sezer Acar, Behzat Özkan, Design: Özlem Nalbantoğlu, Sezer Acar, Gülçin Arslan, Behzat Özkan, Data Collection or Processing: Özlem Nalbantoğlu, Sezer Acar, Analysis or Interpretation: Özlem Nalbantoğlu, Sezer Acar, Özge Köprülü, Behzat Özkan, Literature Search: Özlem Nalbantoğlu, Sezer Acar, Özge Köprülü, Behzat Özkan, Writing: Özlem Nalbantoğlu, Sezer Acar, Özge Köprülü, Behzat Özkan.

Financial Disclosure: The authors declared that this study received no financial support.

\section{References}

1. Satia MC, Mukim AG, Tibrewala KD, Bhavsar MS. A randomized two way cross over study for comparison of absorption of vitamin D3 buccal spray and soft gelatin capsule formulation in healthy subjects and in patients with intestinal malabsorption. Nutr J 2015;14:114.

2. Garland CF, French CB, Baggerly LL, Heaney RP. Vitamin D supplement doses and serum 25-hydroxyvitamin $\mathrm{D}$ in the range associated with cancer prevention. Anticancer Res 2011;31:607-611.

3. Grant WB. Relation between prediagnostic serum 25-hydroxyvitamin D level and incidence of breast, colorectal, and other cancers. J Photochem Photobiol B 2010;101:130-136. Epub 2010 May

4. Anderson JL, May HT, Horne BD, Bair TL, Hall NL, Carlquist JF, Lappé DL, Muhlestein JB; Intermountain Heart Collaborative (IHC) Study Group. Relation of vitamin D deficiency to cardiovascular risk factors, disease status, and incident events in a general healthcare population. Am J Cardiol 2010;106:963-968. Epub 2010 Aug 11

5. Mitri J, Muraru MD, Pittas AG. Vitamin D and type 2 diabetes: a systematic review. Eur J Clin Nutr 2011;65:1005-1015. Epub 2011 Jul 6

6. Khan H, Kunutsor S, Franco OH, Chowdhury R. Vitamin D, type 2 diabetes and other metabolic outcomes: a systematic review and metaanalysis of prospective studies. Proc Nutr Soc 2013;72:89-97. Epub 2012 Oct 30

7. Pittas AG, Nelson J, Mitri J, Hillmann W, Garganta C, Nathan DM, Hu FB, Dawson-Hughes B; Diabetes Prevention Program Research Group. Plasma 25-hydroxyvitamin D and progression to diabetes in patients 
at risk for diabetes: an ancillary analysis in the Diabetes Prevention Program. Diabetes Care 2012;35:565-573. Epub 2012 Feb 8

8. Littorin B, Blom P, Schölin A, Arnqvist HJ, Blohmé G, Bolinder J, Ekbom-Schnell A, Eriksson JW, Gudbjörnsdottir S, Nyström L, Ostman J, Sundkvist G. Lower levels of plasma 25-hydroxyvitamin D among young adults at diagnosis of autoimmune type 1 diabetes compared with control subjects: results from the nationwide Diabetes Incidence Study in Sweden (DISS). Diabetologia 2006;49:2847-2852. Epub 2006 Oct 27

9. Raghuwanshi A, Joshi SS, Christakos S. Vitamin D and multiple sclerosis. J Cell Biochem. 2008;105:338-343.

10. Pappa HM, Gordon CM, Saslowsky TM, Zholudev A, Horr B, Shih MC, Grand RJ. Vitamin D status in children and young adults with inflammatory bowel disease. Pediatrics 2006;118:1950-1961.

11. Munns CF, Shaw N, Kiely M, Specker BL, Thacher TD, Ozono K, Michigami T, Tiosano D, Mughal MZ, Mäkitie O, Ramos-Abad L, Ward L, DiMeglio LA, Atapattu N, Cassinelli H, Braegger C, Pettifor JM, Seth A, Idris HW, Bhatia V, Fu J, Goldberg G, Sävendahl L, Khadgawat R, Pludowski P, Maddock J, Hyppönen E, Oduwole A, Frew E, Aguiar M, Tulchinsky T, Butler G, Högler W. Global consensus recommendations on prevention and management of nutritional rickets. J Clin Endocrinol Metab 2016;101:394-415. Epub 2016 Jan 8

12. Holick MF, Binkley NC, Bischoff-Ferrari HA, Gordon CM, Hanley DA, Heaney RP, Murad MH, Weaver CM; Endocrine Society. Evaluation, treatment, and prevention of vitamin D deficiency: an Endocrine Society clinical practice guideline. J Clin Endocrinol Metab 2011;96:1911-1930. Epub 2011 Jun 6

13. Braegger C, Campoy C, Colomb V, Decsi T, Domellof M, Fewtrell M, Hojsak I, Mihatsch W, Molgaard C, Shamir R, Turck D, van Goudoever J; ESPGHAN Committee on Nutrition. Vitamin D in the healthy European paediatric population. J Pediatr Gastroenterol Nutr 2013;56:692-701.

14. Saggese G, Vierucci F, Prodam F, Cardinale F, Cetin I, Chiappini E, De' Angelis GL, Massari M, Miraglia Del Giudice E, Miraglia Del Giudice M, Peroni D, Terracciano L, Agostiniani R, Careddu D, Ghiglioni DG, Bona G, Di Mauro G, Corsello G. Vitamin D in pediatric age: consensus of the Italian Pediatric Society and the Italian Society of Preventive and Social Pediatrics, jointly with the Italian Federation of Pediatricians. Ital J Pediatr 2018;44:51.

15. Wagner CL, Greer FR; American Academy of Pediatrics Section on Breastfeeding; American Academy of Pediatrics Committee on Nutrition. Prevention of rickets and vitamin D deficiency in infants, children, and adolescents. Pediatrics 2008;122:1142-1152.

16. Grammatikopoulou MG, Gkiouras K, Nigdelis MP, Bogdanos DP, Goulis DG. Efficacy of vitamin D3 buccal spray supplementation compared to other delivery methods: a systematic review of superiority randomized controlled trials. Nutrients 2020;12:691.

17. Todd JJ, McSorley EM, Pourshahidi LK, Madigan SM, Laird E, Healy M, Magee PJ. Vitamin D3 supplementation in healthy adults: a comparison between capsule and oral spray solution as a method of delivery in a wintertime, randomised, open-label, cross-over study. Br J Nutr 2016;116:1402-1408. Epub 2016 Oct 11

18. Williams CE, Williams EA, Corfe BM. Rate of change of circulating 25-hydroxyvitamin D following sublingual and capsular vitamin D preparations. Eur J Clin Nutr 2019;73:1630-1635. Epub 2019 Sep 23

19. Penagini F, Borsani B, Maruca K, Giosia V, Bova S, Mastrangelo M, Zuccotti GV, Mora S. Short-term vitamin D3 supplementation in children with neurodisabilities: comparison of two delivery methods. Horm Res Paediatr 2017;88:281-284. Epub 2017 Sep 12

20. Unsur EK. Vitamin D levels of the healthy infants using oral spray or drop form of vitamin D supplement in the first year of life. North Clin Istanb 2021;8:31-36.

21. Kondolot M, Balci E, Ozturk A, Mazicioglu MM, Hatipoglu N, Kurtoglu $\mathrm{S}$, Ustunbas HB. Body mass index percentiles for Turkish children aged 0-84 months. Ann Hum Biol 2011;38:676-680. Epub 2011 Sep 29

22. Ozturk A, Mazicioglu MM, Hatipoglu N, Budak N, Keskin G, Yazlak Z, Balci N, Yildiz H, Yildiz K, Ustunbas HB, Kurtoglu S. Reference body mass index curves for Turkish children 6 to 18 years of age. J Pediatr Endocrinol Metab 2008;21:827-836.

23. IOM (Institute of Medicine). Dietary reference intakes for calcium and vitamin D. Washington: The National Academies Press; 2011.

24. Malabanan A, Veronikis IE, Holick MF. Redefining vitamin D insufficiency. Lancet 1998;351:805-806

25. Gordon CM, Williams AL, Feldman HA, May J, Sinclair L, Vasquez A, Cox JE. Treatment of hypovitaminosis D in infants and toddlers. J Clin Endocrinol Metab 2008;93:2716-2721. Epub 2008 Apr 15

26. Pappa HM, Mitchell PD, Jiang H, Kassiff S, Filip-Dhima R, DiFabio D, Quinn N, Lawton RC, Varvaris M, Van Straaten S, Gordon CM. Treatment of vitamin D insufficiency in children and adolescents with inflammatory bowel disease: a randomized clinical trial comparing three regimens. J Clin Endocrinol Metab 2012;97:2134-2142. Epub 2012 Mar 28

27. Pritchard L, Lewis S, Hickson M. Comparative effectiveness of vitamin D supplementation via buccal spray versus oral supplements on serum 25-hydroxyvitamin D concentrations in humans: a systematic review protocol. JBI Database System Rev Implement Rep 2019;17:487-499.

28. Žmitek K, Hribar M, Hristov H, Pravst I. Efficiency of vitamin D supplementation in healthy adults is associated with body mass index and baseline serum 25-hydroxyvitamin D level. Nutrients 2020;12:1268.

29. Ekwaru JP, Zwicker JD, Holick MF, Giovannucci E, Veugelers PJ. The importance of body weight for the dose response relationship of oral vitamin D supplementation and serum 25-hydroxyvitamin D in healthy volunteers. PLoS One 2014;9:e111265.

30. Powe CE, Evans MK, Wenger J, Zonderman AB, Berg AH, Nalls M, Tamez H, Zhang D, Bhan I, Karumanchi SA, Powe NR, Thadhani R. Vitamin D-binding protein and vitamin D status of black Americans and white Americans. N Engl J Med 2013;369:1991-2000. 